\title{
Migration/Refugee Law (2019)
}

\author{
Matthew Scott*
}

In 2019 , with nearly 25 million people newly displaced by disasters, ${ }^{1}$ the need to develop, enhance and implement international, regional and national-level legal and policy frameworks to address the phenomenon remained acute. As was the case in 2018, most developments took the form of non-binding statements, guidelines and processes.

Where 2018 was dominated by a number of important international and regional policy developments, notably the processes leading to the U NGA's affirmation of the Global Compact on Refugees (GCR) and the Global Compact on Safe, Orderly and Regular Migration (GCM), the most significant development for 2019 was jurisprudential. In October 2019, the Human Rights Committee adopted views in the case of Teitiota $v$ New Zealand. ${ }^{2}$ The case clarified the scope of the non-refoulement obligation under Article 6 (right to life) of the International Covenant on Civil and Political Rights (ICCPR). ${ }^{3}$ This chapter will examine the decision in some detail before turning to other developments.

\section{International Developments}

\subsection{Decision of the Human Rights Committee in Teitiota $v$ New Zealand}

On 24 October 2019, the Human Rights Committee (CCPR) adopted its views in the case of Teitiota $v$ New Zealand. ${ }^{4}$ Mr Teitiota claimed that his expulsion from

* Senior researcher, head of People on the Move thematic area, Raoul Wallenberg Institute of Human Rights and Humanitarian Law. Contributions from UnHCR (Isabelle Michal, Madeline Garlick and Kees Wouters), Iом (Pablo Escribano, Ileana-Sinziana Puscas, and Alice Sironi) and the Platform on Disaster Displacement (Juan Carlos Méndez) are gratefully acknowledged. Any errors are my own.

1 IDMC, Global Report on Internal Displacement (28 April 2020) <https://www.internal -displacement.org/sites/default/files/publications/documents/2020-IDMC-GRID.pdf> last accessed (as any subsequent URL) in April 2020.

2 CCPR, 'Views adopted by the Committee under article 5 (4) of the Optional Protocol, concerning communication No. 2728/2016' (7 January 2020) CCPR/C/127/D/2728/2016.

3 International Covenant on Civil and Political Rights, adopted 16 December 1966, entered into force 23 March 1976.

4 CCPR/C/127/D/2728/2016 (7 January 2O2O). 
New Zealand to the small Pacific island nation of Kiribati amounted to a violation of Article 6 (right to life) of the ICCPR.

The communication represented the international-level culmination of litigation, which can be traced back to the first determination of the New Zealand Immigration and Protection Tribunal (NZIPT) in the case of $A F$ (Kiribati). ${ }^{5}$ In that case, Mr Teitiota had argued that his enforced return to Kiribati would amount to a violation of the non-refoulement obligation under the 1951 Convention Relating to the Status of Refugees ${ }^{6}$ and its ${ }_{1967}$ Protocol. ${ }^{7}$ In addition, he argued that his enforced return would amount to a violation of his right to life under Article 6 and his right to be free from cruel, inhuman or degrading treatment or punishment under Article 7 of the ICCPR. The NZIPT had dismissed the claim under both the Refugee Convention and the ICCPR in a determination that was ultimately upheld by the Supreme Court of New Zealand. ${ }^{8}$ The reasons for dismissing the claim under the Refugee Convention and Article 7 ICCPR are not relevant to the 2019 decision of the CCPR, and therefore will not be addressed here. ${ }^{9}$

The NZIPT dismissed the claim under Article 6 ICCPR for three reasons. First, the Tribunal concluded that even if Mr Teitiota were to die in the context of disasters and climate change if returned back to Kiribati, such a death could not accurately be described as 'arbitrary' deprivation of life for the purposes of the Covenant because the state was taking steps to address the challenges presented by climate change. ${ }^{10}$ Second, recognizing that climate change presents a serious threat to life in the somewhat longer term, the Tribunal asserted that at present this threat could not be considered 'imminent', and therefore fell outside of the scope of protection of the Covenant." Similar reasoning was further developed in a subsequent case known as AC (Tuvalu). ${ }^{12}$ Finally, considering the evidence relating to current conditions, the Tribunal was not

[2013] NZIPT 800413.

Convention Relating to the Status of Refugees, adopted 28 July 1951, entered into force 22 April 1954.

7 Protocol Relating to the Status of Refugees, adopted 31 January 1967, entered into force 4 October 1967.

8 Ioane Teitiota v. The Chief Executive of the Ministry of Business, Innovation and Employment, [2015] NZSC 107.

9 The case is treated in detail in Matthew Scott, Climate Change, Disasters and the Refugee Convention (CUP 2020).

$10 \quad$ Para 88.

11 Para 91.

12 [2014] NZIPT 8OO517-520. 
satisfied that the kinds of harm the claimant feared being exposed to on return were sufficiently serious as to make his life 'in danger'.13

On all three points, the approach adopted by the CCPR in Teitiota $v$ New Zealand was significantly different, and potentially more expansive, than the approach adopted by the NZIPT in AF (Kiribati). ${ }^{14}$ In relation to the first point, it is important to note that the entirety of the assessment is directed towards the question whether the conduct of the New Zealand authorities amounted to a violation of Article 6 ICCPR. In other words, the question about whether Mr Teitiota had been exposed to an 'arbitrary' deprivation of his right to life is directed not to the receiving country, but to the sending country. This point is made clearly at paragraph 9.7, where the CCPR describes its task as 'assessing whether the State party's authorities provided the author with an adequate and individualized assessment of the risk of a threat to his right to life (...)' On the facts, the CCPR concluded at para 9.12 that it was 'not in a position to conclude that the assessment of the domestic authorities (...) was clearly arbitrary or erroneous (...)'.

On the second point, the CCPR focused the assessment of imminence of the implementation of the decision to remove the claimant, again shifting focus back to the New Zealand authorities, not the Kiribati authorities. The Committee explained that 'in the context of attaining victim status in cases of deportation or extradition, the requirement of imminence primarily attaches to the decision to remove the individual, whereas the imminence of any anticipated harm in the receiving state influences the assessment of the real risk faced by the individual. ${ }^{15}$

On the final and most noteworthy point, concerning the severity of present harm, the CCPR agreed that the evidence did not suggest that Mr Teitiota faced a real risk of being exposed to serious harm if returned. However, the CCPR went significantly further than the NZIPT, recognizing that, in accordance with

\section{Para 91.}

14 It warrants noting that the jurisdiction of the Human Rights Committee is different from the jurisdiction of the NZIPT, which affects to some extent the framing of the decision. Individual communications to the Human Rights Committee are regulated by the Optional Protocol to the International Covenant on Civil and Political Rights. Article 2 provides that individuals may submit claims 'that any of their rights enumerated in the Covenant have been violated and who have exhausted all available domestic remedies'. The focus is therefore very much on the conduct of the contracting state, whereas the NZIPT enquires more closely into the question whether the individual risks being exposed to human rights violations if returned to the country of origin or habitual residence. 
its 2018 General Comment, ${ }^{16}$ the right to life under Article 6 entails not only the right not to be arbitrarily deprived of life, but the right to a life with dignity. ${ }^{17}$ Citing jurisprudence from the Inter-American, African and European regional human rights systems, the CCPR recognised that a person may be deprived of the right to life in the context of 'environmental degradation, climate change and unsustainable development'.18 The right to life may be violated even where 'such threats and situations do not result in the loss of life.'19 On the facts, however, the CCPR was not satisfied that Mr Teitiota faced a reasonably foreseeable threat to his right to life, and therefore dismissed his claim. This decision is likely to lead to significant further development in jurisprudence in the future.

\subsection{The Global Platform for Disaster Risk Reduction}

The issue of disaster displacement remained in focus for the biennial Global Platform for Disaster Risk Reduction. Drawing on discussions and presentations over the course of this 5 day event, paragraphs 6 , 12, and 28 of the Co-Chairs' Summary recognised, respectively, the development of new tools for addressing disaster displacement, the importance of including displaced persons in disaster risk reduction measures, and the need to take steps to reduce displacement risk. ${ }^{20}$

\section{$2.3 \quad$ UNCCD COP 14}

Note $19 /$ COP.14, ${ }^{21}$ prepared in connection with the 14th Conference of Parties (COP) of the UN Convention to Combat Desertification (UNCCD $)^{22}$ focused on the positive role that measures taken under the Convention can play to address desertification/land degradation and drought as one of the drivers that causes migration. It summarises the various ways in which the UNCCD Secretariat

16 CCPR, 'General Comment No. 36 (2018) on Article 6 of the International Covenant on Civil and Political Rights, on the Right to Life' (3o October 2018) CCPR/C/GC/36. Consider para. 26, which provides indications of the breadth of the scope of the concept of life with dignity, which includes, amongst a host of other factors, matters relating to disaster risk reduction and a host of economic, social and cultural rights.

17 Para 9.4.

18 Para $9 \cdot 4-9.5$.

19 Para 9.4.

20 GPDRR, Co-Chairs' Summary: Resilience Dividend: Towards Sustainable and Inclusive Societies $(2019)<$ https://www.preventionweb.net/files/588o9_chairsummary.pdf >.

21 UNCCD, 'The positive role that measures taken under the Convention can play to address desertification/land degradation and drought as one of the drivers that causes migration' (ICCD/COP(14)/19) 24 June 2019.

22 United Nations Convention to Combat Desertification in those Countries Experiencing Serious Drought and/or Desertification, Particularly in Africa, adopted 14 October 1994, entered into force 26 December 1996. 
has assisted states, and endorses the study, prepared by the International Organization for Migration (IOM) and the UNCCD, on 'Addressing the Land Degradation - Migration Nexus: The Role of the United Nations Convention to Combat Desertification.23

\section{$2.4 \quad$ UNFCCC COP 25}

A number of events relating to climate change, migration and displacement were held during COP 25 in Madrid, including a 'high-level thematic session' on the topic. ${ }^{24}$ Additionally, following endorsement by the Parties of the recommendations of the Warsaw International Mechanism Task Force on Displacement (TFD) at COP 24 in December 2018, the Executive Committee subsequently adopted the new terms of reference of the TFD in March 2019, launching the second phase of the TFD. In October 2019, another milestone was reached when the Executive Committee endorsed the new Plan of Action of the TFD. ${ }^{25}$

\subsection{Appointment of High-Level Panel on Internal Displacement}

On 23 October 2019, the UN Secretary General announced his decision to constitute a High Level Expert Panel on Internal Displacement, ${ }^{26}$ responding, perhaps, in part to concerns raised that the GCM and GCR had failed to adequately engage with this phenomenon. ${ }^{27}$ The terms of reference charge panel members with responsibility for drawing 'international attention to the issue of internal displacement and its impact' and to 'prepare a report to the UN Secretary-General with concrete and practical recommendations to Member States, the United Nations system, and other relevant stakeholders on how to better respond to internal displacement (...).'28 The report will, amongst

23 IOM and UNCCD, 'Addressing the Land Degradation - Migration Nexus: The Role of the United Nations Convention to Combat Desertification (IOM and UNCCD, 2019), $<$ https://environmentalmigration.iom.int/sites/default/files/IOM\%2oUNCCD\%20 Desertification\%202019\%2oFINAL.pdf>.

24 For details of events see <https://environmentalmigration.iom.int/human-mobility -cop25>.

25 See UNFCCC, 'Report of the Executive Committee of the Warsaw International Mechanism for Loss and Damage Associated with Climate Change Impacts', (15 November 2019) FCCC/SB/2019/5/Add.1, including the Plan of Action in Annex 1.

26 See <https://www.un.org/internal-displacement-panel/content/high-level-panel>.

27 See for example T Alexander Aleinikoff, 'The Unfinished Work of the Global Compact on Refugees', (2018) 30 International Journal of Refugee Law, 611.

28 United Nations, 'Terms of Reference: Expert Advisory Group for the High-level Panel on Internal Displacement; (undated), 2 <https://www.icvanetwork.org/system/files/ver sions/ToRs\%2OHLP\%2oDecember\%202019\%2OFINAL.pdf>. 
other contributions, provide recommendations for ' [a]dvancing collaboration between humanitarian, development, and where appropriate climate change adaptation, disaster risk reduction and peace actors, to better support affected Member States in addressing and reducing internal displacement and facilitating the exchange of lessons and good practices among affected states and other relevant actors. ${ }^{29}$

\subsection{Global Refugee Forum}

Following the significant adoption in 2018 of the $\mathrm{GCR}^{30}{ }^{30} 2019$ provided the first opportunity for the convening of the Global Refugee Forum, envisaged at paragraphs 17-19 of the Compact as a ministerial level event designed to promote concrete implementation. The Forum was held from 16-18 December in Geneva. ${ }^{31}$ Around 40 states and stakeholders made pledges in relation to climate change, primarily in areas relating to sustainable energy. There were no pledges relating specifically to the legal status of people who move internally or across international borders in the context of disasters and climate change. However, the Marshall Islands was one of the few states to make a more general commitment to addressing the issue, pledging:

To support regional and sub regional cooperation, processes and frameworks related to addressing root causes, strengthen preparedness and enhance capacity to avert, minimize and address internal and external displacement as a result of disaster, environmental degradation and the adverse effects of climate change, and to join the Group of Friends of the Platform on Disaster Displacement and support its work in the Pacific and elsewhere.

A related pledge was made by Mauritius, and Zimbabwe committed to 'organizing a regional symposium on the impact of climate change on protection and humanitarian issues.' ${ }^{32}$

\footnotetext{
$29 \quad$ Ibid.

30 On which see Volker Türk and Madeline Garlick, 'Addressing Displacement in the Context of Disasters and the Adverse Effects of Climate Change: Elements and Opportunities in the Global Compact on Refugees', (2019) 31 International Journal of Refugee Law, 389.

31 UNHCR, Summary of the First Global Refugee Forum by the Co-Convenors (18 December 2019) <https://www.unhcr.org/5dfa7oe24>.

32 See <https://globalcompactrefugees.org/channel/pledges-contributions > for further details of pledges and contributions.
} 


\section{Regional Developments}

\subsection{Africa}

At the regional level, displacement in the context of disasters and climate change received significant high-level attention. Reflecting the significance of the inclusion of disaster- and climate change related displacement and migration in the G CM, the 3 Year Implementation Plan of Action for the Global Compact on Safe, Orderly and Regular Migration (GCM) in Africa (20202022), ${ }^{33}$ presented at the 3 rd Ordinary Session of the Specialized Technical Committee on Migration, Refugees and Internally Displaced Persons from 4-8 November 2019, identified four action points of specific relevance, relating to analysis, adaptation and resilience strategies, integrating displacement considerations into disaster preparedness strategies, and harmonizing and developing approaches and mechanisms to address the vulnerabilities of people moving in this context.

The Plan of Action was presented towards the end of the year, which had been declared by the African Union as the Year of Refugees, Returnees and IDPs. ${ }^{34}$ The declaration recognized that disasters and climate change 'can exacerbate existing violent conflict, threaten access to vital resources and disproportionately affect the most vulnerable and result in displacement'. ${ }^{35}$

Building expressly on the momentum generated by the Year of Refugees, Returnees and IDPs, the Network of African National Human Rights Institutions (NANHRI), in collaboration with the African Union, adopted a 'Declaration and Action Plan on National Human Rights Institutions Contribution to Durable Solutions on Forced Displacements in Africa'. The six-point Action Plan recognizes disasters and climate change amongst the 'diverse drivers of displacement on the continent'. Adopting an expressly human rights-based approach, the Action Plan includes points on reviewing national law and policy, monitoring particular instances of displacement and promoting access to justice and awareness raising. This initiative, which was endorsed on 4 November 2019 at the NANHRI annual meeting, ${ }^{36}$ has significant potential to enhance national

33 See <https://au.int/sites/default/files/newsevents/workingdocuments/37472-wd-3_year _implementation_plan_of_action-english.pdf>.

34 African Union, 'Declaration on the African Union Theme of the Year 2019: "The Year of Refugees, Returnees and Internally Displaced Persons: Towards Durable solutions to Forced Displacement in Africa", Assembly/AU/Decl.8 (XXXII) (10-11 February, 2019). $<$ https://au.int/sites/default/files/decisions/36461-assembly_au_dec_713_-_748_xxxii _e.pdf $>$.

35 Para. 16.

36 Email from NANHRI Secretariat dated 10 March 2020, on file with the author. 
and regional-level law, policy and practice relating to displacement in the context of disasters and climate change.

\subsection{Asia and the Pacific}

The International Organization for Migration, together with partners including UN agencies and the Pacific Islands Forum Secretariat, initiated a programme entitled 'Enhancing Protection and Empowerment of Migrants and Communities Affected by Climate Change and Disasters in the Pacific Region'. The initiative will target Fiji, Kiribati, Tuvalu, Republic of the Marshall Islands and Vanuatu. It promotes:

A regional framework and to strengthen community-based solutions for addressing the multi-faceted challenges posed by climate insecurity in the Pacific region, focusing on climate-induced and disaster-related migration, displacement and planned relocation. ${ }^{37}$

The programme runs until 2022. ${ }^{38}$

The Republic of Fiji issued Displacement Guidelines in the Context of Climate Change and Disasters, ${ }^{39}$ with sections on 'pre-displacement process', 'in-displacement process', 'post-displacement' process and 'permanent displacement'. The Guidelines are firmly grounded in key international standards, guidelines and processes, and adopt an expressly human rights-based approach.

\subsection{The Americas}

At the regional level, member countries of the Caribbean Migration Consultations (CMC) developed a draft 'Plan of Action to Address Human Mobility in the Context of Disasters and the Adverse Effects of Climate Change in the Caribbean (2020-2022)', which is intended to be endorsed by CMC high-level authorities by the end of 2020. Building on existing global frameworks, including the Sendai Framework, the two Global Compacts and the UNFCCC, the Plan of Action provides a set of recommendations around three components:

- Managing displacement risk and building resilience, addressing the environmental drivers of forced migration

37 See $<$ https://www.un.org/humansecurity/hsprogramme/pacificislands/ $>$.

38 See $<$ https://reliefweb.int/report/world/climate-change-and-migration-project-launched -protect-empower-pacific-communities $>$.

39 See <https://www.pacificclimatechange.net/sites/default/files/documents/Displacement \%2oGuidelines.\%2oIn\%2othe\%2ocontext\%2oof\%2oclimate\%2ochange\%2oand\%2o disasters.pdf $>$. 
- Protecting and addressing the needs and rights of persons displaced by climate change and disaster and environmental migrants in the Caribbean and

- Migration as adaptation: experiences and challenges in using mobility to avoid harm and promote adaptation.

Peru approved in December 2019 a new regulation for its 2018 Climate Change Framework Law through Executive Decree o13-2019-MINAM ('Reglamento de la Ley No 30754, Ley Marco sobre Cambio Climático No o13-2019-MINAM'). The regulation requires the Environment Ministry to develop, in coordination with the Ministry of Women and Vulnerable Populations, a 'Plan of action to prevent and address forced migration due to climate change.'This Plan of Action is currently under development and it is expected to be concluded in 2020.

In El Salvador a new Immigration Law ('Ley especial de Migración y de Extranjería') entered into force on 25 April 2019, which extends the legal stay of tourists if their country of origin is affected by 'natural phenomena' among other humanitarian and anthropogenic considerations (Article 85). Based on this Law, on 24 May 2019 a new regulation entered into force ('Reglamento de la Ley Especial de Migración y Extranjería') which grants residence on humanitarian grounds to a person whose life is threatened in his/her country of origin due to natural/environmental disasters, a humanitarian crisis internationally recognized, among others (Article 181).

\subsection{Europe}

Both the European Parliament and the Parliamentary Assembly of the Council of Europe expressed concern about the implications of climate change on cross-border displacement.

On 28 November, the European Parliament adopted resolution 2019/2712 (RSP) at the 2019 UN Climate Change Conference in Madrid, Spain. The resolution recognised the 'deepening implications of climate change' including in relation to 'climate-induced displacement' and urged the EU and Member States to work with partners around to the world to 'better understand, integrate, anticipate and manage the destabilising effects of climate change (...)'. The resolution is silent on the question of internal displacement within the European Union and does not address the question of cross-border displacement into the European Union either.

In contrast, Resolution 2307(2019) of the Parliamentary Assembly of the Council of Europe on a Legal Status for 'Climate Refugees' 40 calls for the development 'in the asylum systems of member States and in international law

40 See $<$ http://assembly.coe.int/nw/xml/XRef/Xref-XML2HTML-en.asp?fileid=28239\&lang $=$ en $>$. 
protection for people fleeing long-term climate change in their native country'. The resolution further asserts that ' $t]$ he industrialised member States of the Council of Europe carry a particular responsibility to those countries, especially the countries of the "global South" affected by man-made climate change, and should therefore provide appropriate asylum for climate refugees'.

This resolution of the Parliamentary Assembly of the Council of Europe represents a bold call for a significant broadening of existing domestic and regional-level mechanisms for addressing claims for international protection brought by individuals fearing exposure to serious harm in the context of disasters and climate change in their home countries. However, the Resolution comes at a time of particular political aversion to refugees movements into Europe, reflected most prominently in the 2020 decision by Greece to deny access to its asylum procedure..$^{41}$ The tension between border control and international protection is likely to increase as the impacts of climate change continue to contribute to migration and displacement.

41 For information on this development, see Matthew Scott, 'Key issues arising from the decision of the Greek government to close its border with Turkey' (6 March 2020) <https:// rwi.lu.se/2020/03/key-issues-arising-from-the-decision-of-the-greek-government-to -close-its-border-with-turkey/>. 